\title{
Analysis of Syntactic Errors in College English Writing
}

\author{
Dongmei Sheng \\ Foreign Language Department, Jilin Business and Technology College, Changchun, China \\ 455635403@qq.com
}

Keywords: Composition; Error analysis; Overgeneralization; English writing

\begin{abstract}
The aim of this study is to search for the best teaching method to help the college students in their writing. This paper presents an analysis of the distribution of syntactic errors in college students' composition, which are incomplete sentence structure, improper use of conjunctions, errors of coordinate relation and Chinese English. The result shows that the main reasons of the syntactic errors are attributed to the transfer of mother tongue and over generalization. The author also puts forward the teaching suggestion and the meaning of error analysis. The result suggests that the better teaching method in college students' writing is of great significance in improving college students' writing ability.
\end{abstract}

\section{Introduction}

In the process of second language acquisition, learners will make some language errors and these errors can not be avoided. This phenomenon is particularly prominent in the process of College English writing. From the scores of Band- four level tests, the pass rate, most of the students' writing ability is still weak. For a long time, the problem plagued a large number of English learners, especially non English major students. How to improve students' English writing level is task the majority of English teachers face. In this regard, many experts and scholars have made unremitting efforts.

\section{Review of Error Analysis Theory}

Error analysis rises in 1960s.In the late 70's in the United States it was criticized and neglected because of the rise of the second language. Although its status has risen, it has not been restored to the original level, and can only be used as a relatively strong subject and interpretation of language teaching and learning problems in the auxiliary role. But in the United States, the situation is different, as comparative analysis and error analysis in Europe is very popular. Definition of the error is defined as work as the unsuccessful part of the language. The definition of error analysis is the process of studying the appearance, nature, causes and consequences of unsuccessful language.

The data collection of error analysis of includes two steps. The first step is the universal collection, which makes a preliminary understanding of the learner's writing level. The second step is the deep analysis on the error. One expert illustrates the relationship between word frequency and their English language proficiency on the base of statistics. Another expert shows that cultivating students' awareness of sentence, paragraph, textual and sense of style is to improve the students' English writing ability and writing level of effective means and so on. These studies have analyzed the causes of students' English writing ability and the problems in English teaching from different perspectives, which makes teachers aware of the necessity and feasibility of improving the teaching methods. In order to improve college students' English writing level and make it reach the standard of National College English test, the author believes that it should start with the analysis of the errors in writing. Only if we find the source of the error, we can carry out the appropriate correction. Empirical analysis.

The author makes an empirical analysis on the composition of the first grade students of non English majors. According to the requirements of the four level of College English writing, students will finish at least 120 words in 30 minutes. Then the author uses induction and comparative analysis to analyze students' mistakes in the composition. The results show that the errors in the 
compositions are particularly prominent. Errors in words and phrases, accounted for second. The error of the sentence level is more common and is affect the semantic expression, discourse level analysis. Therefore, it is of great help to improve the writing ability, strengthen the training of the sentence level and correct the mistakes of the English sentence patterns. The first five syntax errors in the top of list are: incomplete sentence structure, conjunctions used improperly, parallel error and unknown sentences, Chinese English.

Incomplete sentence structure refers to the sentence of the lack of subject, predicate and other components. The phrase or the sentence is taken as a complete sentence. For example: By attending recreational activities on campus can cultivate students' ability. In this sentence, the preposition phrase is used as the subject. The right one: Attending recreational activities on campus can cultivate students' ability.

Improper use of conjunctions generally exits in nominal clauses, attributive clauses and other clauses. The error is that the associated word is not used or the wrong word is used. A conjunction is a word that is used to link the various parts of a sentence. Although there are setbacks, but racial relations are still improving. In Chinese, "though" or "but" is reasonable to match, but in English these two words can not be used with each other. Although there are setbacks, racial relations are still improving. "For example, doing some exercises is good for our health, it is important to get up and do some exercise every morning. There is no conjunction in this sentence. "so" can be used in this sentence; Doing some exercises is good for our health, so it is important to get up and do some exercise every morning. Error of coordinate relation: if part of speech and structure are not consistent, this will lead to the syntactic parallelism error in writing. For example: my mother is not only a strict teacher but also she is like our good friend. "Not only, but also" The connection does not meet the requirements in the part of speech and parallel structure. The right sentence: My mother is not only a strict teacher but also a good friend. Chinese English, as a special phenomenon, often occurs in Chinese students' compositions. Due to the inevitable or even positive comparison between English learners and native speakers, these result in forming an English statement in the use of Chinese language, called negative transfer. If the sentence structure of English and Chinese is consistent with the positive transfer, the learning of English is useful. However, negative transfer interferes with the structure of English sentences. Chinese English includes many fields of language errors. According to the structure and meaning of the sentence, Chinese English is divided into three types. For example: Golden weeks occur make the benefit to customers and businessmen.

\section{Teaching Suggestions and Significance}

Through the analysis of the causes of the error, the author found that most of the errors after certain training can be overcome. How to correct these errors and improve the level of English writing is the major task of English teachers and researchers to explore. According to the teaching experience, the author puts forward some suggestions: minimize the impact of negative transfer of mother tongue. The teacher may guide students to learn authentic English sentence patterns and constantly recite and imitate to cultivate English thinking mode. The students should distinguish Chinese and English difference. For Special English sentence patterns, especially in Chinese, there are no sentence patterns. Consolidate the knowledge of English grammar; master the rules of grammar and flexible application. Grammar is the basis of writing. The application of grammar can not be limited to understanding. Understanding and coping with the level of standardized test questions is difficult for English teachers. For the compound sentence, the clause of the request can be reflected in the written expression. English teachers should develop students' ability to recognize and correct grammatical errors. English training should be guaranteed to give students a multi-level correct language input. Particularly, teacher should pay attention to the neglect of students. The students found problems in a timely manner to correct.

\section{Conclusion}

This research aims to investigate the IL features of Chinese students' language. After the data 
analysis and discussion, the following conclusions can be drawn.

Errors accompany the whole stages of language learning process, and the study of error is carried out by means of Error Analysis. EA theory has aroused great attention and has been explored and applied by many researchers at home and abroad in their academic writings. For the intermediate learners, syntactical errors are the most important part of all errors. The major findings in the dissertation may be summarized as the following:

First of all, as the intermediate learners, college students commit more errors at the sentence level, a few errors at the word level. The data collected from the dissertation proves that there are a lot of syntactical errors in the college students' dissertations. Secondly, many syntactical errors made by the college students, such as Chinese English, Conjunction, Concord, Sentence structure, word order, others. Thirdly, the syntactic errors come from four sources, which are Chinese Interference, Intralingual errors, Ineffectiveness of teaching and lack of cultural knowledge.

The current study is a small-scale research with limitations in its scope and methodology. However, some implications can be derived from it. The clause, as one of the important English syntactic structures, is not easy for the Chinese learners. They avoid using such complex structures in their writings. However, some potential means may be helpful to encourage the use of the clauses the teacher can manipulate several variables, such as writing task instructions, the writing topics, and sample relative sentences, particularly in the form of proverb or saying. Teachers may acquaint themselves with the Chinese learners' acquisition order of different clauses.As for the errors made in the use of clauses; it is known that learners may follow their own acquisition order, which may not appear completely clear to the teachers now. It is advised that it is more reasonable to encourage more frequent use of the structure rather than to over correct learners.

The current researcher is only an attempt to find out the syntactical errors and their classification from which some findings may be drawn. However, the writer is still in the process of foreign language learning. To discover and explain the syntactical errors made by college students is quite challenging for the language teacher. Problems definitely exist. What I hope with a great expectation is that my research and findings may arouse the college students' attention consideration and logical thinking in coping with their composition.

\section{References}

[1] Anderson, R. Transfer to somewhere. (In. S. Grass \& L. Selinker (eds.) 2013).

[2] Camps, J. Aspectual distinctions in Spanish as a foreign language. IRAL, (2012). 40: 179-210.

[3] Carl, J. Errors in Language Learning and Use: Exploring Error Analysis. (Foreign Language Teaching and Research Press 2010).

[4] Close, R. A. A Reference Grammar for Students of English. (Longman Group. 2015).

[5] Corder, S P. The Significance of Learner' Errors. International Review of Applied Linguistics. , Vol. 56 (2014), No. 5, p161-170.

[6] Collins, L. The Development of Tense and Aspect (Michigan State University, East Lansing, MI. 2007).

[7] Diane Larsen-Freeman; Michael H. Long. An Introduction to Second Language Acquisition Research. (Foreign Language Teaching and Research Press 2015).

[8] Ellis, R. Understanding Second Language Acquisition. Oxford: Oxford University Press (2008). No 7 P.52-53.

[9] Gorbet, F. Error Analysis and Child Acquisition (2013). p 22-28.

[10]James, G. Addison Limited Wesley Longman. (2014) 51-234. 